\title{
Comparison of regenerated and non-regenerated oxidized cellulose hemostatic agents
}

\author{
K. M. Lewis · D. Spazierer · M. D. Urban · L. Lin · H. Redl · A. Goppelt
}

Received: 1 September 2012 / Accepted: 3 June 2013 / Published online: 4 July 2013

(c) The Author(s) 2013. This article is published with open access at Springerlink.com

\section{Summary}

Background Oxidized cellulose is a well known and widely used surgical hemostat. It is available in many forms, but manufactured using either a nonregenerated or regenerated process.

Objective This study compares the fiber structure, $\mathrm{pH}$ in solution, bactericidal effectiveness, and hemostatic effectiveness of an oxidized nonregenerated cellulose (ONRC; Traumastem ${ }^{\circledR}$ ) and an oxidized regenerated cellulose (ORC; Surgicel ${ }^{\circledR}$ Original).

Methods In vitro, fiber structures were compared using scanning electron microscopy, $\mathrm{pH}$ of phosphate buffer solution (PBS) and human plasma were measured after each cellulose was submerged, and bactericidal effect was measured by plating each cellulose with four bacteria. In vivo, time to hemostasis and hemostatic success were compared using a general surgery nonheparinized porcine liver abrasion model and a peripheral vascular surgery heparinized leporine femoral vessel bleeding model.

Results Ultrastructure of ONRC fiber is frayed, while ORC is smooth. ORC pH is statistically more acidic than ONRC in PBS, but equal in plasma. No difference in bactericidal effectiveness was observed. In vivo, ONRC provided superior time to hemostasis relative to ORC (211.2 vs $384.6 \mathrm{~s}, N=60$ /group) in the general surgery model;

K. M. Lewis, DVM ( $₫) \cdot$ M. D. Urban, HT (ASCP) · L. Lin, PhD Baxter Healthcare Corporation, One Baxter Parkway, Deerfield, IL 60015, USA

e-mail: kevin_lewis@baxter.com

D. Spazierer, $\mathrm{PhD} \cdot \mathrm{A}$. Goppelt, $\mathrm{PhD}$

Baxter Innovations GmbH, Wagramerstrasse 17-19, 1220 Vienna, Austria

\section{H. Redl, PhD}

Ludwig Boltzmann Institute for Experimental and Clinical Traumatology, AUVA Research Center Austrian Cluster for Tissue Regeneration, Vienna, Austria and superior hemostatic success relative to ORC at 30 (60 vs. $15 \%$; OR: 13.5; $95 \%$ CI: 3.72-49.1, $N=40$ /group), 60 (85 vs. $37.5 \%$; OR: 12.3 ; $95 \%$ CI: $3.66-41.6$ ), and $90 \mathrm{~s}$ (97.5 vs $70.0 \%$; OR: $21.1,95 \%$ CI: $2.28-195.9$ ) in the peripheral vascular model.

Conclusion ONRC provides superior hemostasis and equivalent bactericidal effectiveness relative to ORC, which is likely due to its fiber structure than acidity.

Keywords Traumastem · Surgicel $\cdot$ Cellulose $\cdot$ Oxidized cellulose - Hemostasis - Liver abrasion - Liver square · Celstat · Fibrin pad

\section{Introduction}

Intraoperative bleeding prolongs surgical procedures and, if untreated, can lead to secondary complications. A number of adjunctive hemostatic agents can be used to achieve hemostasis [1], of which topical thrombin, porcine collagen, and oxidized cellulose were originally used. Oxidized cellulose was first used in 1945 [2], and since then it is widely used in all surgical specialties and available in many different forms. Oxidized cellulose is well known and accepted because of its ease of use, favorable biocompatibility, and bactericidal properties.

Oxidized cellulose is a sterile, ready-to-use hemostatic gauze. Cellulose is a homopolysaccharide of glucopyranose polymerized through $\beta$-glucosidic bonds [3]. Cellulose can be either regenerated to form organized fibers or remain nonregenerated with unorganized fibers prior to oxidation. When cellulose fibers are treated with dinitrogen tetroxide, hydoxyl groups are oxidized into carboxylic acid groups yielding a polyuronic acid [4]. While polyuronic acid is the main component of oxidized cellulose, nonoxidized hydroxyl groups remain as a fibrous component. 
The two components of oxidized cellulose undergo disparate in vivo degradation processes. The polyuronic acid is depolymerized by $\beta$-elimination facilitated by glycosidases within $18 \mathrm{~h}$ after implantation, and the fibrous component is phagocytized and then hydrolyzed by local macrophage $[3,5,6]$. The oxidization process makes cellulose susceptible to glycosidases, but also gives oxidized cellulose its hemostatic and bactericidal properties.

The low $\mathrm{pH}$ of the carboxylic acid groups generates a primary local hemostyptic action and secondary platelet activation to form a temporary platelet plug [4]. The low $\mathrm{pH}$ of carboxylic acid groups also generates conditions under which most bacteria cannot survive [7]. The bactericidal properties increase as greater concentrations of dinitrogen tetroxide are used to oxidize cellulose [8]. The bactericidal properties of oxidized cellulose are also dependent on the knit structure and thickness, where thinner loose-knit patterns are less effective than thicker tight-knit patterns against antibiotic-resistant microorganisms [9]. Since both the hemostatic and bactericidal effects are affiliated with the low $\mathrm{pH}$ generated by carboxylic acid, our hypothesis is that the hemostatic properties-like the bactericidal properties_of oxidized cellulose are also affected by the fiber structure and thickness.

Therefore, the objective of this study is to compare the fiber, $\mathrm{pH}$ in solution, bactericidal effectiveness, and hemostatic effectiveness of an oxidized nonregenerated cellulose (Traumastem ${ }^{\circledR}$, Bioster a.s., Czech Republic) and an oxidized regenerated cellulose (Surgicel ${ }^{\circledR}$ Original, Ethicon, Inc., New Jersey, USA). The hypothesis of the study is that the oxidized nonregenerated cellulose (Traumastem ${ }^{\circledR}$ ) will have a greater surface area as seen on scanning electron microscopy, an equivalent $\mathrm{pH}$ in solution, a greater bactericidal effectiveness, and a greater in vivo effectiveness based on a nonheparinized porcine hepatic abrasion model and a heparinized leporine femoral vein model.

\section{Materials and methods}

\section{Oxidized cellulose agents}

Traumastem is nonregenerated oxidized cellulose, which is also known as Celstat in North America. Surgicel Original is regenerated oxidized cellulose, which is also known as Tabotamp in Europe.

\section{In vitro comparisons}

Ultrastructure Scanning electron microscopy (SEM) was used to compare the ultrastructure of the oxidized cellulose products. A strip of each material was cut and mounted onto aluminum stubs with carbon tape. Samples were then photographed and coated with palladium gold with a sputter coater (EMITECH SC7620, Quorum Technologies, Ltd., West Sussex, UK). The coated material was examined using a Jeol JSM-6510 Scanning Elec- tron Microscope (Jeol USA, Inc., Peabody, Massachusetts, USA) and representative images were taken from both materials in the same magnification.

$p H$ in solution The $\mathrm{pH}$ of phosphate buffer solution (PBS; Invitrogen, Grand Island, New York, USA) and pooled human plasma (Baxter AG, Vienna, Austria) was measured 12,30 , and $60 \mathrm{~min}$ after a $2 \times 2 \mathrm{~cm}$ piece of oxidized cellulose was submerged in solution. An additional 90 min time point was added for plasma. A total of nine $\mathrm{pH}$ measurements were taken at each time point.

Bactericidal activity Pieces of oxidized cellulose and sterile gauze were cut to weigh $150 \pm 2 \mathrm{mg}$ and individually placed into a sterile Falcon test tube (BD, Franklin Lakes, New Jersey, USA). A $166 \mu \mathrm{L}$ sample of Staphylococcus aureus (ATCC 6538, $4.7 \times 10^{7} \mathrm{CFU}$ ), Streptococcus pyogenes (ATCC 19615, 4.5 $\times 10^{7}$ ), Pseudomonas aeruginosa (ATCC $9027,6.1 \times 10^{7} \mathrm{CFU}$ ), or Enterococcus faecium (ATCC $6057,5.7 \times 10^{7} \mathrm{CFU}$ ) and $3 \mathrm{ml}$ of TSB-Bouillon broth were added to each tube and maintained at $37^{\circ} \mathrm{C}$. Two samples from each tube were taken at $0,1,6$, and $24 \mathrm{~h}$ after being added to the tube. The samples were then plated for $24 \mathrm{~h}$ at $37^{\circ} \mathrm{C}$ after which Colony Forming Units (CFUs) were counted.

\section{In vivo comparisons}

Two in vivo models were used to compare the hemostatic effectiveness of the oxidized cellulose products, one mimicking general surgery and the other peripheral vascular surgery. The nonheparinized porcine hepatic square model was used to compare time to hemostasis and hemostatic success $10 \mathrm{~min}$ after application [10]. A heparinized leporine femoral vein bleeding model was used to compare hemostatic success at 30,60, and $90 \mathrm{~s}$ after application. All animal activities were performed according to the United States Animal Welfare Act and The Guide for the Care and Use of Laboratory Animals in an AAALAC accredited institution.

The nonheparinized porcine hepatic square model was performed by incising a pair of $1 \times 1 \mathrm{~cm}$ squares into the hepatic capsule, then avulsing the capsule $2-3 \mathrm{~mm}$ deep to create a diffuse mixed bleed of venous, venule, and arteriole strength. The square lesions were then treated with a single ply of oxidized cellulose cut to $2 \times 2 \mathrm{~cm}$ squares. The oxidized cellulose products were applied in pairs randomized to one of the two paired lesions. A total of 60 lesions per group were performed across five female pigs weighing $30-35 \mathrm{~kg}$. A single surgeon, who created and treated the lesions, was blinded to treatment and the randomization scheme. The surgeon blotted both lesions, then applied the hemostats with $30 \mathrm{~s}$ of even digital pressure, after which they remained untouched and observed for $10 \mathrm{~min}$. The time to hemostasis was recorded in seconds and hemostatic success was determined at $10 \mathrm{~min}$. The minimum time to hemostasis that could be recorded was $30 \mathrm{~s}$ and the maximum 
was $600 \mathrm{~s}$. Hemostatic success was defined as no bleeding or minimal ooze. Representative lesions treated with oxidized cellulose were collected for immunohistochemisty and stained brown using a primary mouse monoclonal antibody against human fibrinogen and fibrin (American Diagnostica Inc., Stamford, CT, USA) and a primary mouse monoclonal antibody against human Selectin $\mathrm{P}$ antigen (also known as CD62P) on platelets (Lifespan BioSciences, Seattle, WA, USA). Each primary antibody was labeled with a secondary antibody, Mouse-on-Farma HRP-Polymer (BioCare Medical, Concord, CA, USA).

The heparinized leporine femoral vein model was performed by exposing the femoral veins bilaterally and passing a $5 \mathrm{~mm}$ length of 5-0 polyglactin 910 on an RB-1 taper needle in a proximal-to-distal direction through each vein. The proximal and distal bleeds of each vein were then treated with a single ply of oxidized cellulose cut to $1 \times 1 \mathrm{~cm}$. The oxidized cellulose products were applied in pairs randomized to one of the two paired lesions. A total of 40 lesions per group were performed across 20 female New Zealand white rabbits weighing 3.0-3.5 kg. Two surgeons created and treated the lesions. The hemostats were applied as described above and observed for $90 \mathrm{~s}$. An initial bleed rate was measured from each lesion prior to treatment using preweighed gauze for $10 \mathrm{~s}$. The bleed rate of "g/10 s" was converted to " $\mathrm{ml} / \mathrm{min}$ " using $1 \mathrm{~g}$ equaling $1 \mathrm{ml}$ [11]. Hemostatic success was defined as no bleeding and assessed at 30,60, and $90 \mathrm{~s}$ after treatment. The more strict definition of hemostatic success and the use of heparin served to reflect the cardiovascular surgical condition and increase the sensitivity of the animal model. Once hemostasis was achieved a second series of identical lesions were performed distal of the first series. All rabbits were heparinized (300 IU/kg, I.V.) approximately $30 \mathrm{~min}$ prior to the first lesion series.

\section{Statistical analysis}

\section{In vitro $\mathrm{pH}$ comparison}

The $\mathrm{pH}$ difference between nonregenerated and regenerated oxidized cellulose groups submerged in PBS at 12, 30, 60 min and plasma at 12, 30, 60 and 90 min were estimated (SAS procedure MIXED). The mean difference and its $95 \%$ confidence interval were computed and statistical significance defined as $p<0.05$.

Nonheparinized porcine hepatic square model This general surgery model was designed to detect the geometric mean ratio of "regenerated/nonregenerated" equaling 1.25 based on log time to hemostasis. The standard deviation of log time to hemostasis was conservatively assumed to be 0.35 , where 53 lesions per group were required with a two-sided $\alpha$ of 0.05 and power of 0.9. A total of five animals were used to create a total of 120 lesions ( $N=60$ lesions per group) to assure statistically meaningful results. The analysis of covariance (SAS procedure MIXED) on log transformed seconds to hemosta- sis data was performed. Independent variables included the treatment groups. Covariates included pig, liver lobe (left lateral, medial, or right lateral), and baseline bleeding rate (pretreatment). The geometric mean ratio of "regenerated/nonregenerated" and its $95 \%$ confidence interval were computed. If any of the covariate effects, except the baseline bleeding score, were not significant $(p>0.05)$, the analysis was based on the reduced model of those covariates that were statistically significant $(p<0.05)$.

Heparinized leporine femoral vein bleeding model This peripheral vascular model was designed to detect a difference in rates of $80 \%$ versus $40 \%$ with $\alpha=0.05$ and power $=90 \%$ based on a standard test of equal proportions per time point. Forty lesions per group were required with a two-sided $\alpha$ of 0.05 and power of 0.9 . A total of 20 rabbits, each having four lesions each, were used to create a total of 80 lesions ( $N=40$ per group). A logistic regression model (SAS procedure GENMOD) was performed based on the success odds ratios of each treatment. Independent variables included the treatment groups. Covariates included the hind limb (right or left), location (proximal or distal), and initial bleeding. If any of the covariate effects, except the baseline bleeding score, were not significant $(p>0.05)$, the analysis was based on the reduced model of those covariates that were statistically significant $(p<0.05)$.

\section{Results}

\section{In vitro comparisons}

The gross appearance of the oxidized cellulose products did not remarkably differ; however, the ultrastructural appearance did (Fig. 1). Nonregenerated oxidized cellulose had frayed fibers, while regenerated oxidized cellulose had condensed fibers. The knit tightness was visually equal.

The $\mathrm{pH}$ of PBS with nonregenerated oxidized cellulose relative to regenerated oxidized cellulose was significantly higher at all time points (Table 1). Whereas, the $\mathrm{pH}$ of human pooled plasma with nonregenerated oxidized cellulose was not statistically different at all time points but $12 \mathrm{~min}$ relative to regenerated oxidized cellulose (Table 1).

The bactericidal effect of the oxidized cellulose products was identical except against E. faecium at $1 \mathrm{~h}$ (Fig. 2). The bactericidal effects, however, did not differ after $6 \mathrm{~h}$ against E. faecium. As expected, the negative control gauze had no bactericidal effect over time.

\section{In vivo comparisons}

Nonregenerated cellulose $\left(\right.$ Traumastem ${ }^{\circledR}$ ) provided superior shorter median time to hemostasis than regenerated cellulose (Surgicel ${ }^{\circledR}$ Original) in the nonheparinized porcine hepatic square model (211.2 vs $384.6 \mathrm{~s}, N=60$ per 
Fig. 1 Gross and ultrastructural appearance of Traumastem ${ }^{\circledast}$, a nonregenerated oxidized cellulose $(\mathbf{a}, \mathbf{c})$, and Surgicel ${ }^{\circledR}$ Original, a regenerated oxidized cellulose $(\mathbf{b}, \mathbf{d})$
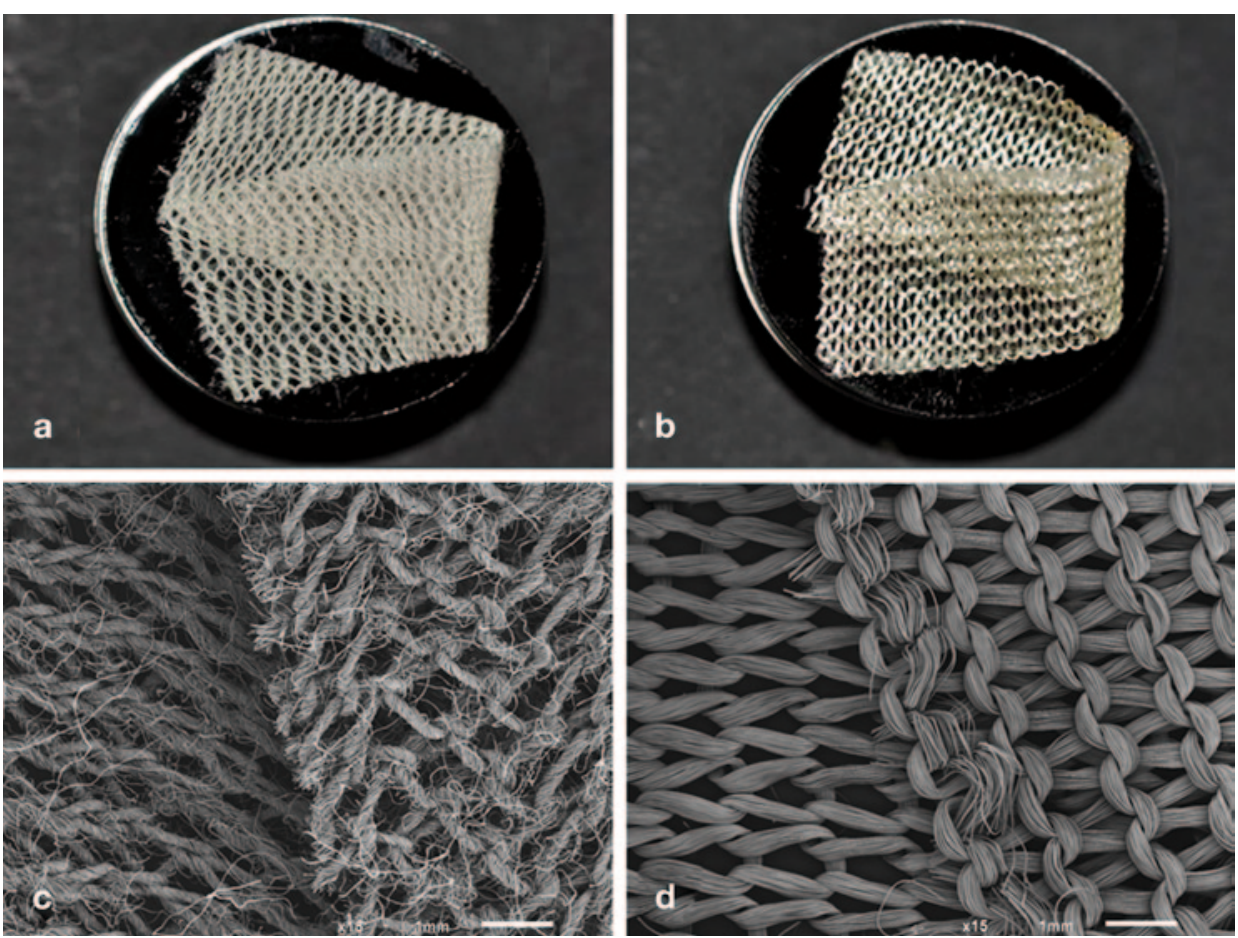

Table $1 \mathrm{Mean} \mathrm{pH}$ of solution at various time points after submersion of Traumastem ${ }^{\circledR}$, a nonregenerated oxidized cellulose, and Surgice ${ }^{\circledR}$ Original, a regenerated oxidized cellulose

\begin{tabular}{|c|c|c|c|c|c|c|c|}
\hline \multirow[t]{2}{*}{ Solution } & \multirow{2}{*}{$\begin{array}{l}\text { Time point } \\
\text { (minutes) }\end{array}$} & \multicolumn{2}{|c|}{ Mean $\mathrm{pH}$ of solution ${ }^{\mathrm{a}}$} & \multirow[t]{2}{*}{ Mean difference } & \multicolumn{2}{|c|}{$95 \%$ confidence limit } & \multirow[t]{2}{*}{$P$ value } \\
\hline & & Traumastem & Surgicel & & Lower & Upper & \\
\hline \multirow[t]{3}{*}{ PBS } & 12 & $1.92 \pm 0.05$ & $1.82 \pm 0.03$ & 0.10 & 0.08 & 0.12 & $<0.0001$ \\
\hline & 30 & $1.92 \pm 0.05$ & $1.81 \pm 0.03$ & 0.11 & 0.09 & 0.13 & $<0.0001$ \\
\hline & 60 & $1.91 \pm 0.05$ & $1.80 \pm 0.02$ & 0.10 & 0.08 & 0.12 & $<0.0001$ \\
\hline \multirow[t]{4}{*}{ Plasma } & 12 & $3.72 \pm 0.22$ & $3.48 \pm 0.10$ & 0.24 & 0.14 & 0.33 & 0.0002 \\
\hline & 30 & $3.50 \pm 0.17$ & $3.41 \pm 0.09$ & 0.09 & -0.00 & 0.18 & 0.0611 \\
\hline & 60 & $3.39 \pm 0.15$ & $3.37 \pm 0.08$ & 0.02 & -0.07 & 0.11 & 0.6058 \\
\hline & 90 & $3.35 \pm 0.13$ & $3.37 \pm 0.06$ & -0.02 & -0.08 & 0.05 & 0.5694 \\
\hline
\end{tabular}

group; Fig. 3). The statistical significance is based on the geometric mean ratio of "regenerated/nonregenerated" equaling 1.857 (95\% CI: 1.669-2.065), which is far greater than 1.0 representing superiority of nonregenerated cellulose. The hemostatic success at $10 \mathrm{~min}$ after application was greater in the nonregenerated cellulose treatment group relative to the regenerated cellulose treatment group ( 100 vs $96.6 \%, N=60$ per group). The amount of bleeding was consistently visually greater from the regenerated cellulose treated lesions than the nonregenerated cellulose treated lesions (Fig. 4). The excess blood loss of the regenerated cellulose treated lesions is observed by the increased fibrin formation and platelet activation histologically (Fig. 5). Both oxidized celluloses have a characteristic ghost appearance histologically because each is dissolved during histological processing [12].

Similarly, nonregenerated cellulose (Traumastem ${ }^{\circledR}$ ) provided superior hemostasis in the heparinized lepo- rine femoral bleeding model relative to regenerated cellulose (Surgicel ${ }^{\circledR}$ Original; Fig. 6). The success of nonregenerated cellulose was superior to regenerated cellulose based on Odds Ratio of Success (OR, "nonregenerated/regenerated") at $30 \mathrm{~s}$ (60 vs. 15\%; OR: 13.5; 95\% CI: $3.72-49.1, N=40$ per group), 60 s (85 vs. $37.5 \%$; OR: 12.3 ; $95 \%$ CI: 3.66-41.6), and 90 s (97.5 vs $70.0 \%$; OR: 21.1, $95 \%$ CI: 2.28-195.9). These $95 \%$ confidence limits of OR at 30,60, and $90 \mathrm{~s}$ are far greater than 1.0 representing superiority of nonregenerated cellulose. The initial bleeding prior to treatment was similar in both groups ( $3.44 \pm 1.8$ vs $3.60 \pm 1.8 \mathrm{ml} / \mathrm{min}, N=40$ per group).

\section{Discussion}

To our knowledge, this is the first study to compare the in vitro and in vivo properties of nonregenerated and regen- 
Staphylococcus aureus (ATCC 6538)

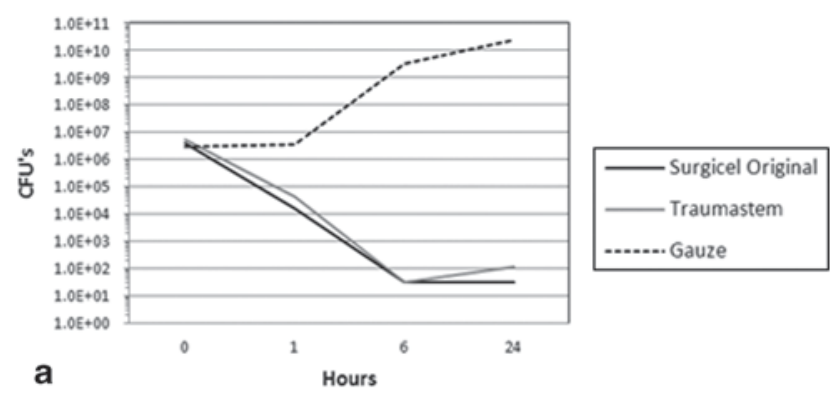

Pseudomonas aeruginosa (ATCC 9027)

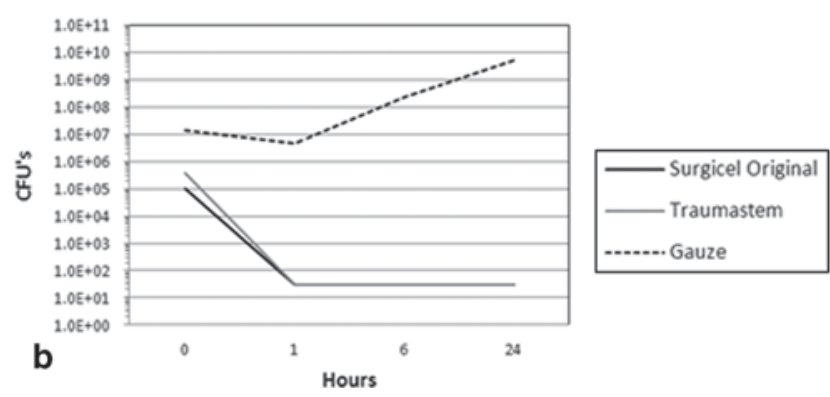

Streptococcus pyogenes (ATCC 19615)

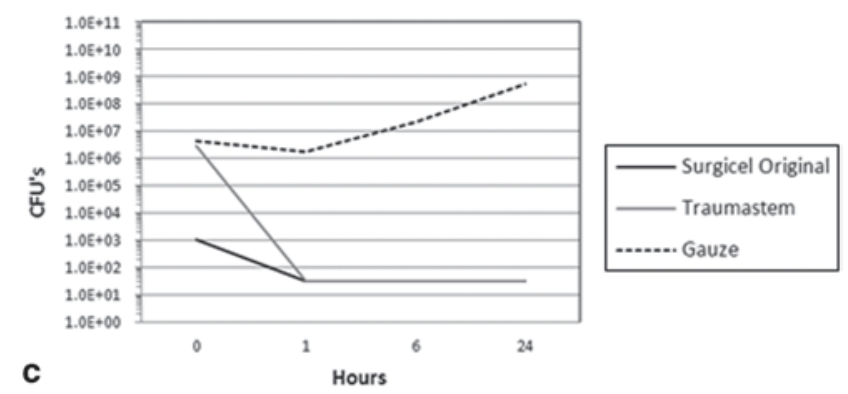

Enterococcus faecium (ATCC 6057)

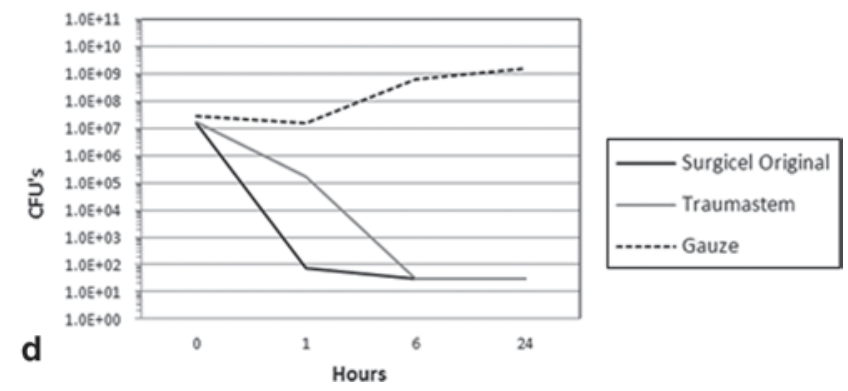

Fig. 2 Bactericidal effect of Traumastem ${ }^{\circledR}$, non-regenerated oxidized cellulose, and Surgice ${ }^{\circledR}$ Original, regenerated oxidized cellulose, against a Staphylococcus aureus (ATCC 6538), b Pseudomonas aeruginosa (ATCC 9027), c Streptococcus pyogenes (ATCC 19615), and $\mathbf{d}$ Enterococcus faecium (ATCC 6057) relative to a sterile gauze negative control. Time point 0 represents baseline colony forming units (CFUs) prior to treatment

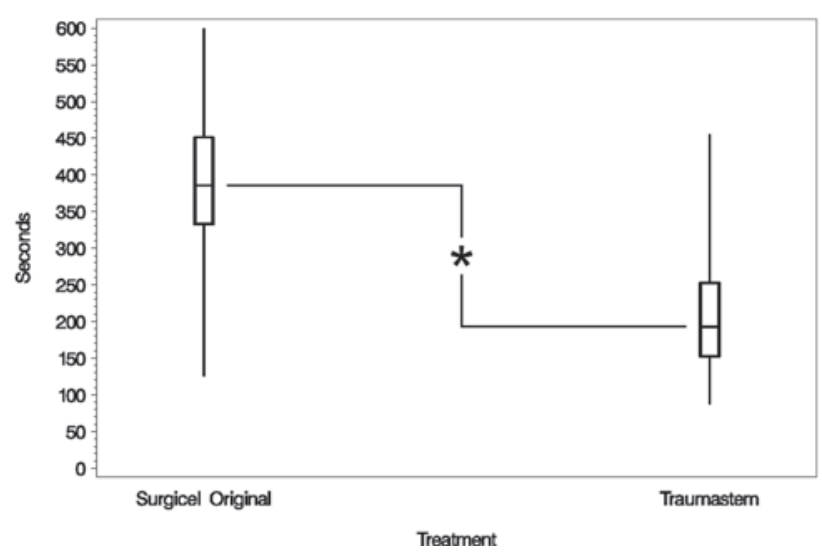

Fig. 3 Box plot of the time to hemostasis in a nonheparinized porcine hepatic square model ( $N=60$ lesions per group). Traumastem $^{\circledast}$, a nonregenerated oxidized cellulose, provides superior hemostasis relative to Surgicel ${ }^{\circledR}$ Original, a regenerated oxidized cellulose ( ${ }^{*}$ statistical significance based on geometrical mean ratio of 1.857 [95\% Cl: 1.669-2.065]). Range, 25th, 50th, and 75th percentiles are depicted

erated oxidized cellulose. The in vitro comparisons demonstrated different fiber structures, different $\mathrm{pH}$ while in PBS, and similar pH while in human plasma, but did not detect a bactericidal difference. The in vivo hemostasis models demonstrated that nonregenerated oxidized cellulose provided superior hemostasis. It was unexpected that bactericidal differences would not be detected while hemostatic differences would be detected, because both

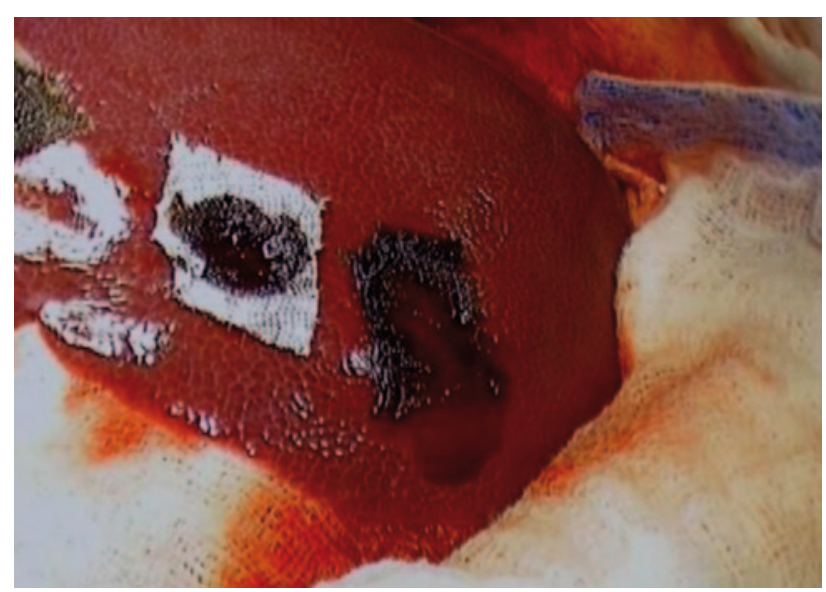

Fig. 4 Representative hepatic square lesions on the lateral aspect of the left lateral lobe treated with Traumastem ${ }^{\circledast}$, a nonregenerated cellulose (left), and Surgice ${ }^{\circledR}$ Original, a regenerated cellulose (right); where excess blood loss is observed from the regenerated cellulose treated lesion, while hemostasis is provided by nonregenerated cellulose

effects are a result of the materials' $\mathrm{pH}$. Since the $\mathrm{pH}$ of each is similar in human plasma, the difference in hemostatic performance is likely a result of the frayed fibers of the nonregenerated oxidized cellulose, which are seen in the SEM images. The frayed fibers of nonregenerated oxidized cellulose create a greater surface area than that of the regenerated oxidized cellulose. 
Fig. 5 Representative hepatic square lesions treated with Traumastem ${ }^{\circledast}$, a nonregenerated cellulose (left images), and Surgicel ${ }^{\circledR}$, a regenerated oxidized cellulose (right images) stained brown with a monoclonal antibody against fibrin (upper images) and the CD62 antigen on platelets (lower images). Images are $10 x$, insets are 40x. Surgicel ${ }^{\circledast}$ treated lesions have greater fibrin and platelets due to excessive bleeding, while Traumastem ${ }^{\circledast}$ treated lesions have less fibrin and platelets due to faster time to hemostasis. $T$ Traumastem ${ }^{\circledR}$, $S$ Surgice ${ }^{\circledast}, L$ Liver, $F$ Fibrin, $P$ Platelets

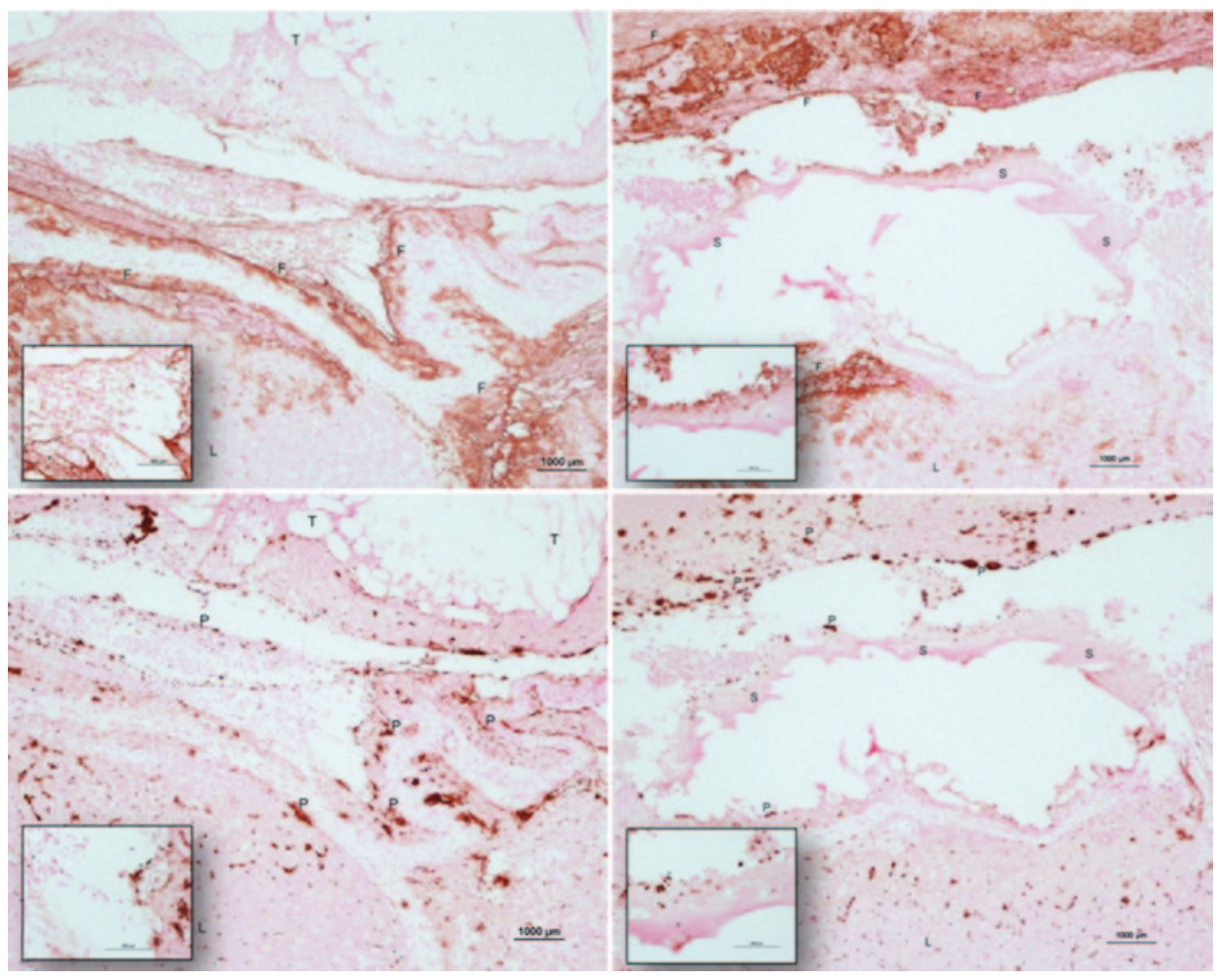

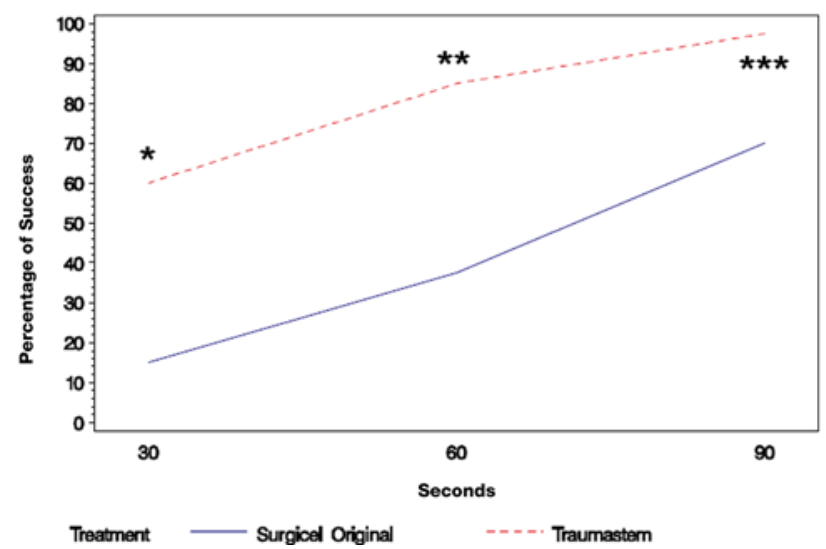

Fig. 6 Hemostatic success 30,60, and 90 s after treatment for Traumastem ${ }^{\circledast}$, a nonregenerated cellulose, and Surgicel ${ }^{\circledR}$ Original, a regenerated cellulose, in a heparinized leporine femoral bleeding model ( $N=40$ lesions per group). Traumastem ${ }^{\oplus}$ is superior to Surgicel ${ }^{\circledR}$ at all time points based on an odds ratio of success (* 13.5 [95\% Cl: 3.72-49.1]; ** 12.3 [3.66-41.6]; *** $21.1[2.28-195.9])$

The in vivo hemostatic performance of nonregenerated oxidized cellulose was superior of regenerated oxidized cellulose in both the non-heparinized porcine hepatic square model and heparinized leporine femoral vein bleeding model. The greatest performance differences were seen in time to hemostasis rather than $10 \mathrm{~min}$ after application in the general surgery model, where median time to hemostasis of nonregenerated oxidized cellulose was half of regenerated oxidized cellulose. Similarly, in the peripheral vascular model, nonregenerated oxidized cellulose had two times greater hemostatic success than regenerated oxidized cellulose 30 and $60 \mathrm{~s}$ after application. Though regenerated cellulose improved at $90 \mathrm{~s}$ after application, nonregenerated oxidized cellulose was still superior to regenerated oxidized cellulose with a difference of $17.5 \%$. While clinical data comparing these two agents are not available, the superior performance of nonregenerated cellulose in these models is expected to be clinically meaningful.

The preclinical models were designed to have high clinical predictability to the clinical setting. The general surgery model was selected because of the high acceptance and use of swine as a hemostatic model [10, 13]. The vascular surgery model was designed such that coagulation differences between rabbits and humans were minimized by heparinization. Heparin, $300 \mathrm{IU} / \mathrm{kg}$, was administered $30 \mathrm{~min}$ prior to creating the vascular lesions to target an activated clotting time 1.8-2.0x baseline as is required in humans for peripheral vascular surgery [14]. Therefore, the preclinical models are expected to be clinically predictive for effectiveness. In regard to safety, no intraoperative side effects or signs of toxicity were observed during these studies. The resorption time of regenerated oxidized cellulose depends on several factors and is not fully known, as reported by the manufacturer; while, the resorption time of nonregenerated oxidized cellulose is known to be 8 days in animal studies.

The ability to improve the hemostatic performance of either nonregenerated or regenerated oxidized cellulose is limited without neutralizing the carboxylic acid groups. The low $\mathrm{pH}$ of oxidized cellulose immediately denatures plasma proteins (e.g., thrombin, fibrinogen, tissue factor, etc.). Co-administration of oxidized cellulose and thrombin, fibrinogen, or alike, renders these plasma proteins ineffective. The low $\mathrm{pH}$ of oxidized cellulose is necessary for its hemostyptic and bactericidal properties. 
Unlike the hemostatic properties, the bactericidal properties of oxidized cellulose can be enhanced by modification with silver and zinc ions [15].

The bactericidal effect of nonregenerated and regenerated oxidized cellulose was identical against all bacteria tested except $E$. faecium. The difference between the celluloses was only observed $1 \mathrm{~h}$ after plating. The reason for the difference is not known, but the difference was resolved at $6 \mathrm{~h}$ after plating. Spangler et al. reported the bactericidal effectiveness of regenerated oxidized cellulose against $P$. aeruginosa and $S$. aureus [9]. In their report regenerated oxidized cellulose had a similar effectiveness against $P$. aeruginosa, but less effectiveness against $S$. aureus relative to our report. The $5 \log$ unit difference between the studies of regenerated oxidized cellulose against $S$. aureus was seen $6 \mathrm{~h}$ after being plated and was resolved by $24 \mathrm{~h}$ after being plated. Sprangler used $165 \pm 5 \mathrm{mg}$ of regenerated oxidized cellulose, whereas we used $150 \pm 2 \mathrm{mg}$.

Interestingly, the $\mathrm{pH}$ of nonregenerated and regenerated oxidized cellulose differed in PBS, but not in human plasma. The more acidic $\mathrm{pH}$ of regenerated oxidized cellulose is revealed in the less buffered solution of PBS. PBS is an anorganic buffer, which lacks proteins and organic compounds present in plasma. As a result, the $\mathrm{pH}$ of PBS drops quickly as the solution reaches equilibrium. The $\mathrm{pH}$ of plasma too equilibrates, but does so slowly as the carbonate, organic compounds, and anorganic buffers are overcome. The greater acidity of regenerated oxidized cellulose has the potential of inducing greater and undesirable tissue damage in nonbuffered clinical conditions (e.g., acidosis secondary to blood loss or inadequate tissue perfusion). Though the acidity of regenerated oxidized cellulose is greater than nonregenerated oxidized cellulose, no differences in bactericidal effect were observed. This may suggest that a threshold $\mathrm{pH}$ exists, where under no further bactericidal effect is observed.

This study is the first to find that nonregenerated oxidized cellulose has a greater surface area, equivalent bactericidal effect, and superior hemostatic properties in vivo under nonheparinized and heparinized conditions relative to regenerated oxidized cellulose. These findings, further, support the hypothesis that fiber structure and thickness effect hemostatic properties of oxidized cellulose based hemostatic agents. While oxidized cellulose is used in nearly all surgical specialties for its ease of use, biocompatibility and bactericidal properties, the nonregenerated oxidized cellulose is likely to become more favored after additional clinical studies are performed and surgical experiences are gained.

\section{Acknowledgements}

The authors thank Dr. Holly Atlee and Mrs. Angela Mannone for their clinical and technical contributions, Dr. Huub Kreuwel for his scientific and clinical input, and Sylvia Nürnberger for her scanning electron microscopy expertise and examination.

\section{Conflict of interest}

Dr. Lewis, Dr. Lin, and Mr. Urban are employees of Baxter Healthcare Corporation. Dr. Goppelt and Dr. Spazierer are employees of Baxter Innovations $\mathrm{GmbH}$. Dr. Redl is a consultant to Baxter Innovations $\mathrm{GmbH}$. The authors declare affiliations in Disclosures. The studies were performed using sound scientific methods, randomization, blinding, paired comparisons, objective metrics, and appropriate sample sizes to remove any bias from the study designs.

\section{Open Access}

This article is distributed under the terms of the Creative Commons Attribution License which permits any use, distribution, and reproduction in any medium, provided the original author(s) and the source are credited.

\section{References}

1. Spotnitz WD, Burks SG. Hemostats, sealants, and adhesives II: update as well as how and when to use the components of the surgical toolbox. Clin Appl Thromb Hemost. 2010;16:497-514.

2. Frantz VK, Lattes R. Oxidized cellulose-absorbable gauze (cellulosic acid). JAMA. 1945;129:798-801.

3. Pierce AM, Wiebkin OW, Wilson DF. Surgicel ${ }^{\circledR}$ : its fate following implantation. J Oral Pathol. 1984;13(6):661-70.

4. Miller JM, Jackson DA, Collier CS. An investigation of the chemical reactions of oxidized regenerated cellulose. Exp Med Surgery. 1961;19:196.

5. Dimitrijevich SD, Tatarko M, Gracy RW. Biodegradation of oxidized regenerated cellulose. Carbohydr Res. 1990;195:247-56.

6. Dimitrijevich SD, Tatarko M, Gracy RW, Wise GE. Oakford LX. In vivo degradation of oxidized, regenerated cellulose. Carbohydr Res. 1990;198:331-41.

7. Dineen P. The effect of oxidized regenerated cellulose on experimental infected splenotomies. J Surg Res. 1977;23:114-6.

8. Abaev Y, Kaputsky V, Adarchenko A, Sobeshchuk O. Mechanism of antibacterial effects of monocarboxyl cellulose and other ion exchange derivatives of cellulose. Antibiot Med Bioteckhnol. 1986;31:624-8.

9. Spangler D, Rothenburger S, Nguyen K, Jampani H, Weiss $\mathrm{S}$. Bhende S. In vitro antimicrobial activity of oxidized regenerated cellulose against antibiotic-resistant microorganisms. Surg Infect. 2003;4:255-62.

10. Adams G, Manson J, Hasselblad V, Shaw LK, Lawson JH. Acute in-vivo evaluation of bleeding with GelfoamTM plus saline and GelfoamTM plus human thrombin using a liver square lesion model in swine. J Thromb Thrombolysis. 2009;28:1-5.

11. Thornton JA. Estimation of blood loss during surgery. Ann R Coll Surg Engl. 1963;33:164-74.

12. Ribalta T, McCutcheon IE, Neto AG, Gupta D, Kumar AJ, Biddle DA, Langford LA, Bruner JM, Leeds NE, Fuller G. Textiloma (Gossypiboma) mimicking recurrent intracranial tumor. Arch Pathol Lab Med. 2004;128:749-58.

13. Kheirabadi BS, Arnaud F, McCarron R, Murdock AD, Hodge DL, Ritter B, Dubick MA, Blackbourne LH. Development of a standard swine hemorrhage model for efficacy assessment of topical hemostatic agents. J Trauma. 2011;71(1 Suppl):S139-46. 


\section{Original Article}

14. Mabry CD, Thompson BW, Read RC. Activated clotting time (ACT) monitoring of intraoperative heparinization in peripheral vascular surgery. Am J Surg. 1979;138(6):894-900.
15. Vytrasova J, Tylsova A, Brozkova I, Cervenka L, Pejchalova M, Havelka P. Antimicrobial effect of oxidized cellulose salts. J Ind Microbiol Biotechnol. 2008;35:1247-52. 